\title{
Short Communication: Effectiveness of nuclear gene in species and subspecies determination of captive orangutans
}

\author{
MUHAMMAD NURISMADEE ABDUL-MANAN ${ }^{1}$, ABD RAHMAN MOHD-RIDWAN ${ }^{1,2}$, NOR RAHMAN AIFAT ${ }^{1}$, \\ NUR AZIMAH OSMAN ${ }^{1,3}$, MUHAMMAD ABU BAKAR ABDUL-LATIFF ${ }^{4}$, SABAPATHY DHARMALINGAM ${ }^{5}$, \\ BADRUL MUNIR MD-ZAIN \\ ${ }^{1}$ Department of Biological Sciences and Biotechnology, Faculty of Science and Technology, Universiti Kebangsaan Malaysia \\ 43600, Bangi, Selangor, Malaysia. Tel.: +60-389-215954, `email: abgbadd@ukm.edu.my; abgbadd1966@yahoo.com \\ ${ }^{2}$ Centre for Pre-University Studies, Universiti Malaysia Sarawak. 94300, Kota Samarahan, Sarawak, Malaysia \\ ${ }^{3}$ School of Biology, Faculty of Applied Sciences, Universiti Teknologi Mara Negeri Sembilan. 72000 Kuala Pilah, Negeri Sembilan, Malaysia \\ ${ }^{4}$ Centre of Research for Sustainable Uses of Natural Resources, Faculty of Applied Sciences and Technology, Universiti Tun Huss ein Onn Malaysia \\ (Pagoh Campus). 84000, Muar, Johor, Malaysia \\ ${ }^{5}$ Bukit Merah Orang Utan Island Foundation, 34400, Bukit Merah, Perak, Malaysia
}

Manuscript received: 28 May 2020. Revision accepted: 21 July 2020.

\begin{abstract}
Abdul-Manan MN, Mohd-Ridwan AR, Aifat NR, Osman NA, Abdul-Latiff MA, Dharmalingam S, Md-Zain BM. 2020. Short Communication: Effectiveness of nuclear gene in species and subspecies determination of captive orangutans. Biodiversitas 21: 36653669. Genetic identification of captive orangutans is of paramount importance in providing a correct identity that is essential for captive management. Thus, the utility of nuclear DNA sequences was tested in this study to identify the genetic identity of captive orangutans at Bukit Merah Orang Utan Island. Out of 24 DNA samples that were successfully extracted, only 10 orangutan samples were successfully sequenced for the von Willebrand factor (vWF) gene. From the results, this gene was able to separate the genus Pongo at the species level. Distance and character analyses indicated that a clear separation between $P$. pygmaeus and $P$. abelii at the species level. However, the degree of separation at species level was indicated in tree topology with moderate bootstrap values. At the subspecies level of $P$. pygmaeus, this gene was unable to show a clear separation between three Bornean subspecies. All the subspecies were formed clade together with each other. The vMF gene is a good nuclear gene for the study of phylogenetic relationships of orangutans in captivity at the species level, but the genetic identification at subspecies level in the genus level remains unclear. We suggest that future studies should involve multiple independent nuclear markers to increase the probability of getting reliable results.
\end{abstract}

Keywords: Captive orangutan, nuclear DNA, von Willebrand Factor (vMF) gene, phylogenetic, Pongo

\section{INTRODUCTION}

The orangutans, genus Pongo, are the merely available Hominidae (great apes) that exist in Asia on Borneo and Sumatra Island (Loken et al. 2013; Kamaluddin et al. 2019). This genus consists of three different species (Nater et al. 2017), namely, Bornean orangutan (Pongo pygmaeus), Sumatran orangutan (Pongo abelii), and Tapanuli orangutan (Pongo tapanuliensis). Roos et al. (2014) classified the Bornean orangutan into three subspecies, namely, P. p. pygmaeus (Sarawak and Northwest Borneo), P. p. wurmbii (Southwest and Central Borneo), and P. p. morio (Sabah and Northeast Borneo). These subspecies of orangutans were classified based on morphology and genetic study of orangutans by primatologists (Warren et al. 2001; Zhang et al. 2001). The Bornean orangutan is presently red-listed as critically endangered under the IUCN (Ancrenaz et al. 2016). Most of the remaining orangutans live outside the protected area (Meijaard and Wich 2007). Over the years, logging, poaching, habitat loss and illegal trades are the major threats to natural populations of orangutans (Freund et al. 2016; Hardus et al. 2012).
There are five primate families found in Malaysia namely Lorisidae, Tarsiidae, Cercopithecidae, Hylobatidae and Hominidae (Md-Zain et al. 2010). Previous molecular systematic studies on Malaysian primates were more focused on the Cercopithecidae, Tarsiidae, and Lorisidae families rather than Hominidae (Md-Zain et al. 2010, 2019; Abdul-Latiff et al. 2019). These previous phylogenetic studies were all based on mitochondrial DNA (mtDNA) markers. All these studies resolved the taxonomy and systematics of Malaysian primates at species and subspecies level using mtDNA markers. In addition, Warren et al. (2001) had also employed mtDNA to identify the distribution of Bornean orangutan. Zhang et al. (2001) utilized microsatellites and mitochondrial DNA sequences to study the genetic divergence of orangutans in Borneo and Sumatra. Zhi et al. (1996) tried to differentiate orangutan subspecies among natural populations using genetic materials, specifically mitochondrial $16 \mathrm{~S}$ ribosomal RNA sequences, minisatellite loci, and mtDNA restriction fragment length polymorphisms. The findings of this study revealed that Sumatran and Bornean orangutans are largely dissimilar in terms of phylogenetic and genetic distance. However, among isolated populations of Bornean 
orangutans, there is little genetic differentiation, suggesting that gene flow might occur among them recently.

The orangutan identity in captivity is doubtful at the subspecies level. Zoos and ex-situ management may not be able to separate orangutans in different enclosures due to difficulty in differentiating them based on their morphological appearances. However, Kamaluddin et al. (2018) managed to successfully identify all three orangutan subspecies in the Bukit Merah Orang Utan Island and several zoos in Peninsular Malaysia based on mtDNA marker. We extended their work on the same orangutan individual samples of Bukit Merah Orang Utan Island (BMOUI) by using a nuclear marker. The usability of the nuclear DNA marker to identify the subspecies of orangutan has yet to be tested. The von Willebrand factor (vWF) gene is a non-linked nuclear genomic locus selected as a candidate marker. Chaves et al. (1999) had employed this locus in determining phylogenetic relationships of New World monkeys and used orangutan as their outgroup. The study has strongly supported the taxon Callitrichinae as a monophyletic subfamily within Cebidae. The ability and effectiveness of vWF nuclear locus have yet to be tested in portraying the Bornean orangutan phylogenetic relationships at subspecies level. Thus, we presented here the effectiveness of $\mathrm{vWF}$ nuclear locus in portraying orangutan genetic identification in captivity. Bukit Merah Orang Utan Island is located (BMOUI) in Perak state of Peninsular Malaysia was selected as sampling site. Previous genetic identification by Kamaluddin et al. (2018) using mitochondrial D-loop region indicated that BMOUI hosts to all three Bornean subspecies.

\section{MATERIALS AND METHODS}

Noninvasive fresh orangutan fecal samples of orangutans were collected at the Bukit Merah Orang Utan Island (Kamaluddin et al. 2018). We also recollected fresh fecal samples to produce good-quality amplification results. Good quality amplification will provide good quality sequence. Usually, non-invasive samples will produce a low DNA quantity (Costa et al. 2017). The collected fecal samples were stored in $70 \%$ alcohol solution. Preservation of DNA and storage conditions may be useful to ensure the most reliable yield of DNA. Additional blood samples, including one sample of $P$. abelii (Zoo Negara), were collected based on FTA cards available in the Department of Wildlife and National Parks (DWNP) genebank collection (Kamaluddin et al. 2018). DNA was extracted using the innuPREP Stool Kit (Analytik Jena), the DNeasy® Blood \& Tissue Kit, and the innuPREP Forensic Kit (Analytik Jena) following the manufacturer's protocols (Rosli et al. 2011; Aifat et al. 2016).

A 922-bp fragment of the vWF gene introns 11 and 12 has been amplified by polymerase chain reaction (PCR) using Gradient Thermal Cycler (Eppendorf North America, Inc.). PCR was conducted using Red Taq Mix with these following parameters: initial denaturation at $95^{\circ} \mathrm{C}$ for 180 sec, followed by 30 cycles of denaturation at $95^{\circ} \mathrm{C}$ for 15 sec, annealing at $50^{\circ} \mathrm{C}$ for $60 \mathrm{sec}$, extension at $72^{\circ} \mathrm{C}$ for 10 sec and final extension stage at $72^{\circ} \mathrm{C}$ for $10 \mathrm{~min}$. The PCR purification kit (QIAGEN) was used for the purification of PCR products. Purified samples have been sent to Apical Scientific Sdn. Bhd (Malaysia) for DNA sequences.

DNA sequences have been viewed and edited using BioEdit sequence alignment editor version 7.2.5. Sequence similarity searches were conducted using GenBank BLASTn application to validate the DNA sequences obtained. Phylogeny trees were reconstructed using both distance (Neighbor-Joining, NJ) and character method (Maximum Parsimony, MP) analysis using MEGA 7 ClustalW multiple alignment algorithms (Kumar et al. 2016) and PAUP 4.0b10 (Swofford 2002). The NJ tree has been reconstructed using the Kimura 2-Parameter model algorithm. The MP tree was obtained using the TreeBisection-Regrafting (TBR) search level 1 algorithm, in which the initial trees were obtained by randomly adding sequences (ten replicates). Bootstrap analysis was used to test the strength and reliability of the tree branch with 1000 replicates. Chimpanzee (Pan troglodytes) has been selected as an outgroup.

\section{RESULTS AND DISCUSSIONS}

After the final editing process, a total of $549 \mathrm{bp}$ of vWF DNA sequences was obtained. Sequence analysis of vWF nuclear gene showed that $543(87.58 \%)$ conserved characters, $5(0.81 \%)$ variable characters, $3(0.48 \%)$ parsimony-informative, and $2(0.32 \%)$ singleton characters. These characters were obtained without including the outgroup. The average nucleotide frequency shows that the $\mathrm{G}$ base had the highest average $(28.8 \%)$, followed by the $\mathrm{C}$ base $(25.5 \%)$, the $\mathrm{T}$ base $(23.7 \%)$, and the A base $(22.1 \%)$. The pairwise distance of orangutan samples showed an exceptionally low value between a range of 0.000 and 0.001. The pairwise distance between $P$. pygmaeus and $P$. abelii was low at 0.005 . In contrast, Kamaluddin et al. (2018) determined a high genetic distance $(0.150)$ between $P$. pygmaeus and $P$. abelii based on mtDNA data. We did not combine both nuclear and mitochondrial markers for further phylogenetic analysis since both these two markers possess a different evolutionary history.

The NJ tree was separated into two main clades, which consisted of subspecies $P$. pygmaeus and $P$. abelii (Figure 1). However, among subspecies samples in the $P$. pygmaeus clade, the NJ tree was not fully resolved as there was no clear separation among them. This clade was supported by low bootstrap value, at $27 \%$ confidence level. However, $P$. abelii was clearly separated from the $P$. pygmaeus group, forming a clade with the bootstrap value of $82 \%$. Based on the MP phylogeny tree, the value of CI was 0.800 , RI was 0.800 , and the tree length was 24 . The MP tree portrayed the same result as the NJ tree, showing a clear separation between $P$. pygmaeus and $P$. abelii. The clade of $P$. abelii was supported by $74 \%$ bootstrap value. In the MP tree, $P$. pygmaeus subspecies phylogenetic resolution was unresolved with low support of $53 \%$ bootstrap value (Figure 2). 


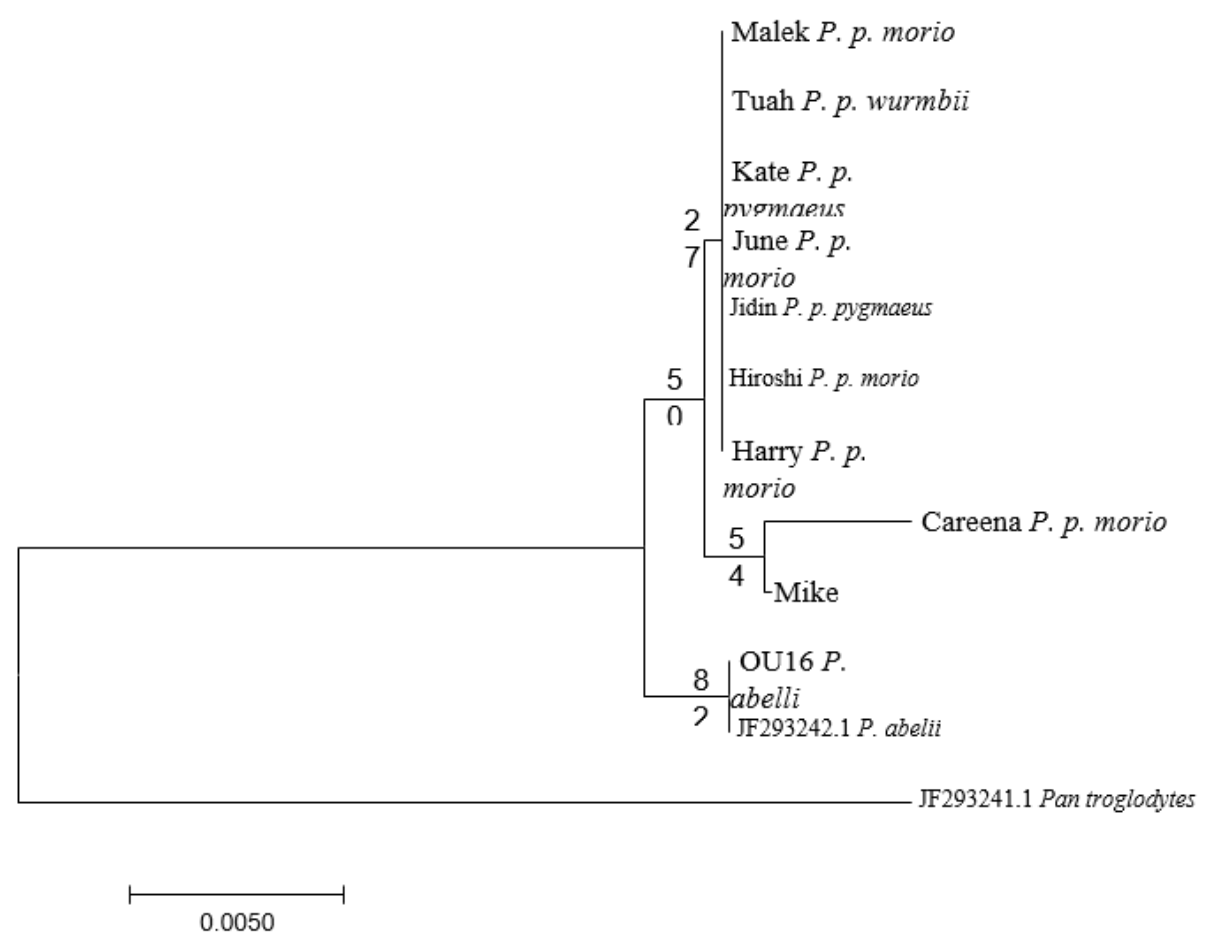

Figure 1. Neighbor-Joining tree generated by Kimura 2-Parameter with bootstrap values on top of branch

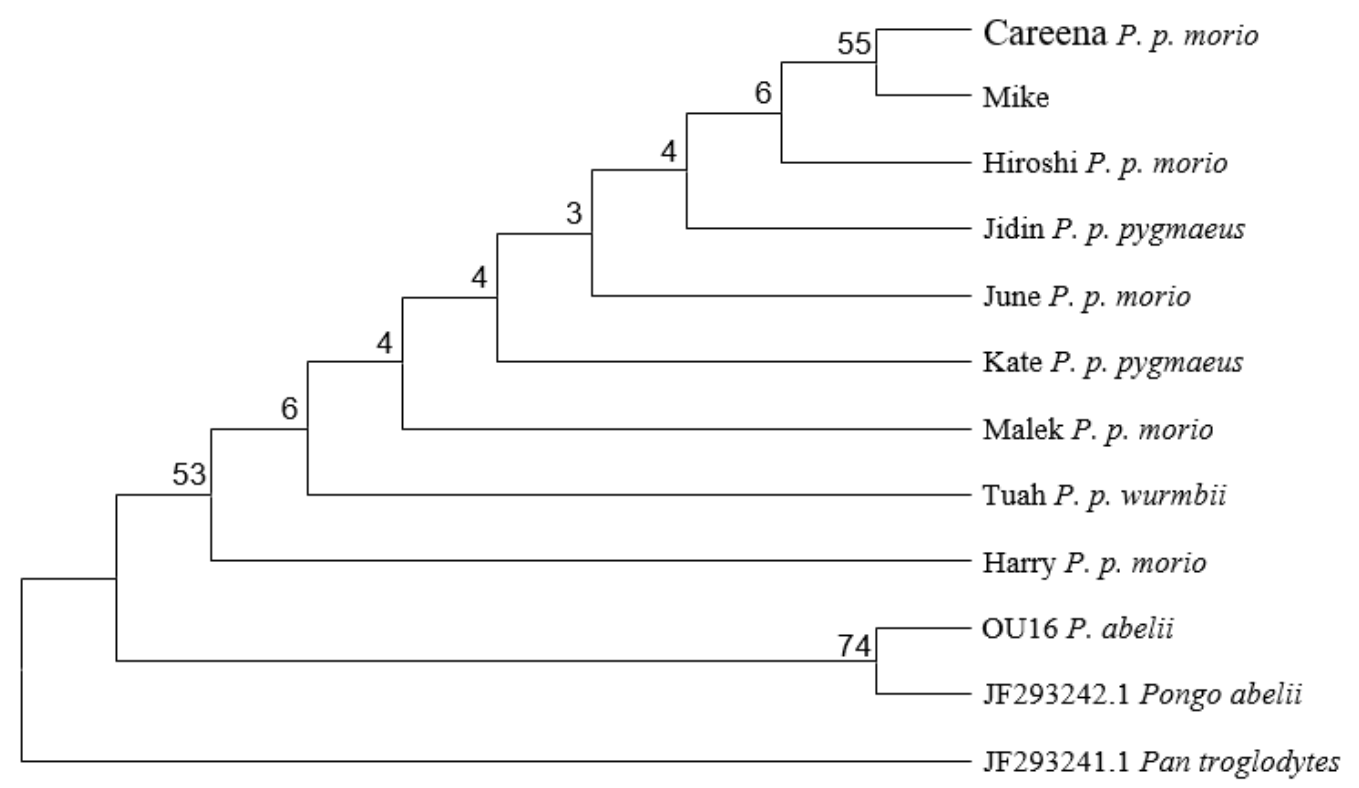

Figure 2. Maximum Parsimony tree generated by heuristic search with bootstrap values on top of branch

Our findings indicated that the nuclear vWF gene is less effective in differentiating subspecies for Bornean orangutan, $P$. pygmaeus. However, this locus can distinguish between the Bornean orangutan and Sumatran orangutan $(P$. abelii). It has been reported that the use of the mtDNA region is more effective in determining the subspecies designation of orangutans (Kamaluddin et al. 2018). The identification of subspecies using the D-loop region on orangutans in captivity had successfully distinguished three subspecies of $P$. pygmaeus, namely, P.p. pygmaeus (Sarawak and Northwest Kalimantan), P. p. wurmbii (Southwest and Central Kalimantan), and P.p. morio (Sabah). The D-loop region has proven to be useful in understanding the phylogenetic relationships between orangutans in captivity, as the control region is the most variable part of mtDNA valuable in systematic molecular 
research (Kamaluddin et al. 2018). In addition, the divergence of $P$. pygmaeus and $P$. abelii was also supported by other studies using different mtDNA loci, such as COII, ND5, or the whole genome (Zhang et al. 2001; Steiper 2006; Goossens et al. 2009).

Our findings revealed a low level of intraspecific divergence between $P$. pygmaeus subspecies using the vWF gene. Some samples of $P$. pygmaeus in our study form polytomy and were grouped together in the same clade, but the relationships were not clearly shown. This is supported by Zhang and Hewitt (2003), indicating the difficulty in clarifying the relationship and producing polytomy due to the low evolutionary rate and low divergence of the vWF gene. It was also reported that the rate of evolution of single-copy nuclear sequences in many vertebrates is significantly lower than that of mtDNA (Zainudin et al. 2010; Yaacov et al. 2012; Ma et al. 2019). Thus, the slow rate of evolution of nuclear DNA is one limitation in our study. In other primate studies, Chaves et al. (1999) successfully placed Callimico goeldii in the callitrichids phylogenetic tree by assessing the vWF gene of intron 11 obtained from a range of different platyrrhine taxa including numerous marmoset species from both the Amazonian and Atlantic forest groups. Moreover, Opazo et al. (2006) validated the existence of three clades (families Pitheciidae, Cebidae, and Atelidae) and strengthened the connection of the Aotus-Saimiri-Cebus group to the callitrichids within the family Cebidae by obtaining orthologous sequences of six nuclear genes including vWF gene and one mitochondrial gene (16S).

Genetic studies of other organisms using nuclear markers have shown similar results to primate studies. For example, the comparison on the effectiveness of mtDNA markers (COI and Cyt $b$ ) and a nuclear marker (RAGI) in mammalian host identification had shown high genetic variations for $\mathrm{COI}$ and Cyt $b$ markers compared to RAGI, suggesting that the nuclear marker is less suitable for species delimitation (Mohammadi et al. 2019). The DNA barcoding study on ray-finned fish using a nuclear gene also failed to correctly identify the species (Liu et al. 2017). Nonetheless, nuclear markers are not suited for taxonomic studies and could not separate the closely related cryptic species quickly and appropriately (Dasmahapatra et al. 2010). In phylogenetic studies, nuclear DNA is suitable for addressing the relationships between classes and orders rather than species levels (Steppan et al. 2004).

Although polymorphism exists in nuclear DNA, the divergence in the pairwise sequence is generally small and in most cases is no more than 1-2\% (Zhang and Hewitt, 2003). Furthermore, analyses of the orangutan genome indicate that genetic exchange between divergent lineages is restricted to reciprocal gene flow (Rogers and Gibbs, 2014). Therefore, conventional phylogenetic analysis methods are not suitable for the analysis of intraspecific polymorphic data because they cannot clearly resolve the evolutionary relationships in the dataset due to the low degree of divergence. Other limiting factors for nuclear DNA include recombination, selection, heterozygosity, insertion or deletion polymorphism, low divergence and polytomy, gene-specific variation in rate and history, and
PCR and DNA sequencing difficulties (Zhang and Hewitt, 2003; Guo et al. 2016).

In conclusion, this study highlights the effectiveness of the vWF gene in portraying orangutan genetic relationships at the species level but not useful at the subspecies level. Thus, the phylogenetic relationships between orangutan subspecies at BMOUI could not be defined due to the low degree of vWF gene variation in the present analysis. However, our results in genetic relationships at species level help to substantiate the phylogenetics of orangutans reported in previous mtDNA studies (Muir et al. 2010; Ma et al. 2013; Banes and Galdikas, 2016; Kamaluddin et al. 2018). Moreover, this knowledge is a prerequisite to the development of a comprehensive and practical approach for conserving Bornean and Sumatran orangutan genetic resources in captivity. We suggest that future studies should examine multiple independent nuclear markers to increase the probability and effectiveness of subspecies identification. It is recommended to use different gene regions in the nuclear DNA, which are longer sequences and higher sequence variations such as Y-chromosomal locus. Captive orangutan genetic identification needs to be carried out for every ex-situ conservation centers. This is to ensure and guiding ex-situ management to possibly minimize existing hybrid orangutans cases.

\section{ACKNOWLEDGEMENTS}

The authors are deeply indebted to Yayasan Emkay and Bukit Merah Orang Utan Island Foundation (Tan Sri Datuk Mustapha Kamal bin Abu Bakar) for providing us funding, facilities, and assistance. We also thank Department of Wildlife and National Parks (PERHILITAN) especially Dr. Jeffrine Rovie Ryan Japning that provided us orangutan genetic samples from BMOUI and Zoo Negara. Research methods reported in this research adhered to the legal requirements of Malaysia and were approved by Department of Wildlife and National Parks under research permit (JPHL\&TN(IP):100-6/1/14 Jld 2(40). The authors acknowledge Universiti Kebangsaan Malaysia for providing funding (TD-2014-022). This research was also supported by Grant ST 2018-020 under Yayasan Emkay.

\section{REFERENCES}

Abdul-Latiff MAB, Baharuddin H, Abdul-Patah P, Md-Zain BM. 2019. Is Malaysia's banded langur, Presbytis femoralis femoralis actually Presbytis neglectus neglectus? Taxonomic revision with new insights on the radiation history of the Presbytis species group in Southeast Asia. Primates 60: 63-79.

Aifat NR, Yaakop S, Md-Zain BM. 2016. Optimization of partial Cyt b gene sequence from selected ancient Presbytis museum skin specimens. Malays Appl Biol 45: 93-96.

Ancrenaz M, Gumal M, Marshall AJ, Meijaard E, Wich SA, Husson S. 2016. Pongo pygmaeus (errata version published in 2018). The IUCN Red List of Threatened Species 2016. www.iucnredlist.org/species/17975/123809220

Banes GL, Galdikas BM. 2016. Effective characterisation of the complete orangutan mitochondrial DNA control region, in the face of persistent focus in many taxa on shorter hypervariable regions. PLoS One 11: e0168715. DOI: 10.1371/journal.pone.0168715 
Chaves R, Sampaio I, Schneider MP, Schneider H, Page SL, Goodman M. 1999. The place of Callimico goeldii in the callithrichine phylogenetic tree: evidence from von Willebrand factor gene intron 11 sequences. Mol Phylogenet Evol 13 (2): 392-404.

Costa V, Rosenbom S, Monteiro R, O'Rourke SM, Beja-Pereira A. 2017. Improving DNA quality extracted from fecal samples- a method to improve DNA yield. Eur J Wildl Res 63 (1): 1-7.

Dasmahapatra KK, Elias M, Hill RI, Hoffman JI, Mallet J. 2010. Mitochondrial DNA barcoding detects some species that are real, and some that are not. Mol Ecol Resour 10 (2): 264-273.

Freund C, Rahman E, Knott C. 2016) Ten years of orangutan-related wildlife crime investigation in West Kalimantan, Indonesia. Am J Primatol 79 (11): 1-11.

Goossens B, Chikhi L, Jalil MF, James S, Ancrenaz M, Lackman, Ancrenaz I, Bruford MW. (2009). Taxonomy, geographic variation and population genetics of Bornean and Sumatran orangutans. In: Wich SA, Utami Atmoko SS, Setia TM, van Schaik CP (eds.). Orangutans: geographic variation in behavioral ecology and conservation. Oxford University Press, Oxford.

Guo C, Du J, Wang L, Yang S, Mauricio R, Tian D, Gu T. 2016. Insertions/deletions-associated nucleotide polymorphism in Arabidopsis thaliana. Front Plant Sci 7: 1792. DOI: 10.3389/fpls.2016.01792.

Hardus ME, Lameira AR, Menken SBJ, Wich SA. 2011. Effects of logging on orangutan behavior. Biol Conserv 146 (1): 177-187.

Kamaluddin SN, Yaakop S, Idris WMR, Dharmalingam S, Rovie-Ryan JJ, Md-Zain BM. 2018. Genetic identification of critically endangered orangutans in captivity. J Sustain Sci Manag 13: 57-68.

Kamaluddin SN, Dharmalingam S, Md-Zain BM. 2019. Positional behavior of captive Bornean Orangutan (Pongo pygmaeus) at Bukit Merah Orangutan Island, Perak, Malaysia. Biodiversitas 20 (2): 425 429

Kumar S, Stecher G, Tamura K. 2016. MEGA 7: molecular evolutionary genetics analysis version 7.0 for bigger datasets. Mol Biol Evol 33 (7): 1870-1874.

Liu J, Jiang J, Song S, Tornabene L, Chabarria R, Naylor GJ, Li C. 2017. Multilocus DNA barcoding-species identification with multilocus data. Sci Rep 7 (1): 16601. DOI: 10.1038/s41598-017-16920-2.

Loken B, Spehar S, Rayadin Y. 2013. Terrestriality in the Bornean orangutan (Pongo pygmaeus morio) and implications for their ecology and conservation. Am J Primatol 75 (11): 1129-1138.

Ma J, Liu J, Shen Y, Fan Z, Yue B, Zhang X. 2019. Population genetic structure and intraspecific genetic distance of Periplaneta americana (Blattodea: Blattidae) based on mitochondrial and nuclear DNA markers. Ecol Evol 9 (22): 12928-12939.

Ma X, Kelley JL, Eilertson K, Musharoff S, Degenhardt JD, Martins AL, Vinar T, Kosiol C, Siepel A, Gutenkunst RN, Bustamante CD. 2013 Population genomic analysis reveals a rich speciation and demographic history of orang-utans (Pongo pygmaeus and Pongo abelii). PLoS One 8: e77175. DOI: 10.1371/journal.pone.0077175

Md-Zain BM, Lee SJ, Lakim M, Ampeng A, Mahani MC. 2010 Phylogenetic position of Tarsius bancanus based on partial Cytochrome $b$ DNA sequences. J Biol Sci 10 (4): 348-354.

Md-Zain BM, Mohhoyua KS, Aifat NR, Ngadi E, Ayob N, Rovie-Ryan JJ, Ampeng A, Mohd-Ridwan AR, Blair ME, Abdul-Latiff MAB 2019. Molecular data confirm the presence of Nycticebus bengalensis on Langkawi Island, Malaysia. Biodiversitas 20 (4): 1115-1120.

Meijaard E, Wich S. (2007). Putting orang-utan population trends into perspective. Curr Biol 17: 14.
Mohammadi Z, Shahabi S, Ghorbani F, Khajeh A. 2019. Efficiency of the mitochondrial DNA markers (COI, cyt b) and a nuclear DNA marker (RAGI) in molecular identification of zoonotic diseases' hosts. J Health Sci Surv Sys 7 (2): 86-93.

Muir CC, Galdikas BM, Beckenbach AT. 2000. MtDNA sequence diversity of orangutans from islands of Borneo and Sumatra. J Mol Evol 51 (5): 471-480.

Nater A, Mattle-Greminger MP, Nurcahyo A, Nowak MG, de Manuel M, Desai T, Groves C, Pybus M, Sonay TB, Roos C, Lameira AR, Wich SA, Askew J, Davila-Ross M, Fredriksson G, de Valles G, Casals F, Prado-Martinez J, Goossens B, Verschoor EJ, Warren KS, Singleton I, Marques DA, Pamungkas J, Perwitasari-Farajallah D, Rianti P, Tuuga A, Gut IG, Gut M, Orozco-terWengel P, van Schaik CP, Bertranpetit J, Anisimova M, Scally A, Marques-Bonet T, Meijaard E, Krützen M. 2017. Morphometric, behavioral, and genomic evidence for a new orangutan species. Curr Biol 27 (22): 3487-3498.

Opazo JC, Wildman DE, Prychitko T, Robert M Johnson RM, Goodman M. 2006. Phylogenetic relationships and divergence times among New World monkeys (Platyrrhini, Primates). Mol Phylogenet Evol 40 (1): 274-280

Rogers J, Gibbs RA. 2014. Comparative primate genomics: emerging patterns of genome content and dynamics. Nat Rev Genet 15: 347359.

Roos C, Boonratana R, Supriatna J, Fellowes JR, Groves CP, Nash SD, Rylands AB, Mittermeier RA. 2014. An updated taxonomy and conservation status review of Asian primates. Asian Primates J 4 (1): 2-38.

Rosli MKA, Zamzuriada AS, Syed-Shabthar SMF, Mahani MC, AbasMazni O, Md-Zain BM. 2011. Optimization PCR conditions to amplify Cyt $b$, COI and 12S rRNA gene fragments of Malayan gaur (Bos gaurus hubbacki) mtDNA. Genet Mol Res 10 (4): 2554-2568.

Steiper ME. (2006). Population history, biogeography, and taxonomy of orangutans (Genus: Pongo) based on a population genetic metaanalysis of multiple loci. J Human Evol 50 (5): 509-522.

Steppan SJ, Storz BL, Hoffmann RS. 2004. Nuclear DNA phylogeny of the squirrels (Mammalia: Rodentia) and the evolution of arboreality from c-myc and RAG1. Mol Phylogenet Evol 30 (3): 703-719.

Swofford DL. 2002 Phylogenetic analysis using parsimony and other methods version 4.0 beta version. Sinauer Associates, Sunderland.

Warren KS, Verschoor EJ, Langenhuijzen S, Swan RA, Vigilant L, Heeney JL. 2001. Speciation and intrasubspecific variation of Bornean orangutans, Pongo pygmaeus pygmaeus. Mol Biol Evol 18 (4): 472-480.

Yaacov DB, Arbel-Thau K, Zilka Y, Ovadia O, Bouskila A, Mishmar D. 2012. Mitochondrial DNA variation, but not nuclear DNA, sharply divides morphologically identical chameleons along an ancient geographic barrier. PLoS One 7: e31372. DOI: 10.1371/journal.pone.0031372

Zainudin R, Shukor MN, Norhayati A, Md-Zain BM, Mustafa AR. 2010. Genetic structure of Hylarana erythraea (Amphibia: Anura: Ranidae) from Malaysia. Zool Stud 49 (5): 88-702.

Zhang DX, Hewitt GM. 2003. Nuclear DNA analyses in genetic studies of populations: practice, problems and prospects. Mol Ecol 12 (3): 563584.

Zhang Y, Ryder OA, Zhang YP. 2001. Genetic divergence of orangutan subspecies (Pongo pygmaeus). J Mol Evol 52 (6): 516-526.

Zhi L, Karesh WB, Janczewski DN, Frazier-Taylor H, Sajuthi D, Gombek F, Andau M, Martenson JS, O’Brien SJ. 1996. Genomic differentiation among natural populations of orang-utan (Pongo pygmaeus). Curr Biol 6 (10): 1326-1336. 